\title{
The Effect of Aerobic Exercise on Blood Pressure and Type of Labor in Primigravidas with Hypertension
}

\author{
Satyawati Sulubara ${ }^{1}$, Hotma Sauhur Hutagaol ${ }^{1} \&$ Eva Mahayani Nasution ${ }^{1}$ \\ ${ }^{1}$ Jurusan Kebidanan, Poltekkes Kemenkes Medan, Medan, Indonesia \\ Correspondence: Rumelia Lubina Sembiring, Comprehensive Emergency Neonatal Obstetrics, RSUD \\ Subulussalam, Aceh, 24782, Indonesia. Tel: 62-813-9604-5555
}

Received: April 23, 2021 Accepted: July 13, 2021 Online Published: August 3, 2021

doi:10.5539/gjhs.v13n9p65 URL: https://doi.org/10.5539/gjhs.v13n9p65

\begin{abstract}
Preeclampsia is one of the main causes of maternal mortality in Indonesia and in the world. The exact cause of preeclampsia is not known at this time. Aerobic exercise as an effort to prevent preeclampsia. The purpose of this study was to determine the effect of aerobic exercise on maternal outcome in primigravidas with a history of hypertension.

This research was a quasy experimental research with pre and post control group. Aerobic exercise was carried out for 15 weeks in the second trimester of pregnancy, then blood pressure measurements were taken in both groups. The data will be analyzed using the $t$-test, and a $p$ value $<0.05$ will be considered statistically significant.

Systolic and diastolic blood pressures were lower in the intervention group than in the control group but not statistically significant, all samples became superimposed preeclampsia and underwent delivery by caesarean section.
\end{abstract}

Keywords: Aerobic exercise, blood pressure, type of labor, primigravida, hypertension

\section{Introduction}

Preeclampsia is one of the main causes of maternal mortality in Indonesia and in the world. The Maternal Mortality Rate (MMR) in Indonesia according to the 2012 Indonesian Demographic Health Survey (IDHS) was 359 per 100,000 live births. The main causes that contributed to the maternal mortality rate were bleeding as much as $32 \%$, hypertension in pregnancy of $25 \%$, infection $5 \%$, prolonged labor $5 \%$, other causes $1 \%$. Other causes, namely $32 \%$ are quite large, including the causes of non-obstetric diseases (Kemenkes, 2012).

Pre-eclampsia during pregnancy is second cause after embolism in the United States. Hypertension in pregnancy is associated with complications, including placental abruption, cerebral hemorrhage, liver failure, and acute renal failure. Preeclampsia, which is one of the hypertension disorders, occurs in $3 \%$ to $4 \%$ of pregnancies and contributes to perinatal morbidity and mortality. Little is known about the development of preeclampsia in terms of modifiable risk factors, such as daily physical activity. Although the health benefits of daily physical activity, such as a reduced risk of essential hypertension, coronary heart disease, and type 2 diabetes are well documented, it is known less about the relationship between maternal physical activity and risk of hypertension, pregnancy disorders (Sorensen, 2003).

Preeclampsia is a condition in which hypertension occurs after the 20th week of pregnancy and is accompanied by proteinuria. In pregnancy with preeclampsia, trophoblast cell invasion occurs only in part of the spiral arteries in the myometrium area, resulting in impaired placental function, so the placenta does not meet the blood needs for nutrients and oxygen to the fetus. This disruption of placental function can cause stunted fetal growth (Sherwood, 2006).

The exact cause of preeclampsia is not known at this time. Preeclampsia is a specific pregnancy syndrome with decreased organ perfusion secondary to vasospame, increased peripheral vascular resistance, and endothelial activation that generally occurs after 20 weeks of gestation. The main sign is an increase in blood pressure accompanied by proteinuria, generalized edema, to impaired clotting function and impaired hepatic function. Risk factors that can increase the incidence of preeclampsia include nulliparous, age less than 20 years or more than 35 years, more than one fetus, diabetes mellitus, chronic hypertension, obesity, and kidney disease. Preeclampsia is also influenced by genetic and environmental factors (Cunningham, 2005). 
Chronic hypertension is pregnant women who already suffer from high blood pressure $(140 / 90 \mathrm{mmHg})$ before pregnancy or before 20 weeks of gestation. Usually chronic hypertension will not go away even though the mother has given birth to the baby. Pregnant women with chronic hypertension or pregnant women with a history of pre-eclampsia have an increased risk of developing pre-eclampsia in their pregnancy and an increase in pregnancy complications, a high risk of delivery by cesarean section and the incidence of LBW (Kasawara, 2013).

Superimposed Preeclampsia is a pregnant woman with chronic hypertension after 20 weeks of pregnancy who experiences edema and urine protein or has the classic triad signs of pre-eclampsia (Module of PPSDM, 2016).

Pregnancy exercise is recommended for pregnant women with hypertension or pregnant women at risk of pre-eclampsia to reduce the adverse effects of hypertension, including reducing the incidence of pre-eclampsia. The goal is to prevent the incidence of pre-eclampsia in pregnancy, by means of lowering blood pressure and cardiovascular improvement, but the results are still few data on the effect of aerobic exercise on the incidence of pre-eclampsia (Kasawara, 2013).

Based on the results of Yeo's research in 2000, that light exercise in the form of aerobic exercise for 10 weeks reduces diastolic blood pressure among pregnant women who are at risk of developing hypertensive disorders. The reduction may be due to the effect of exercise itself, not on physical activity levels or overall. However, this activity does not affect systolic blood pressure (Yeo, 2000).

Aerobic exercise as an effort to prevent preeclampsia is still a controversial matter, so a variety of studies are still needed so that this can be used as a reference in pregnancy care. However, it is based on evidence based that low impact aerobic exercise is not harmful to the health of the mother and fetus and is not related to premature events (Mascio, 2016).

Based on a preliminary survey at Padangmatinggi community health center in 2017, there were 4 cases of pregnant women with preeclampsia.

From the above, the authors are interested in examining the effect of aerobic exercise on blood pressure and type of labor in primigravida mothers with a history of hypertension.

The purpose of this study was to analyze the effect of aerobic exercise on blood pressure and type of delivery in primigravidas with a history of hypertension.

\section{Method of the Study}

\subsection{Participant (Subject) Characteristics}

Appropriate identification of research participants is critical to the science and practice of psychology, particularly for generalizing the findings, making comparisons across replications, and using the evidence in research syntheses and secondary data analyses. If humans participated in the study, report the eligibility and exclusion criteria, including any restrictions based on demographic characteristics.

\subsection{Sampling Procedures}

This study was conducted to analyze the effect of aerobic exercise on blood pressure and type of delivery in primigravidas with a history of hypertension. The population in this study were all primigravida pregnant women with a history of hypertension in Padangsidimpuan city.

The sample chosen was the sample in this study were all populations that met the inclusion and exclusion criteria. The inclusion criteria in this study were age 20-35, second trimester Primigravida and history of Hypertension 140/90 mmHg. The exclusion criteria were heart disease.

The number of samples taken must be the same between the two groups so that the research results are more significant. The sample in this study was the total population, namely all primigravida mothers with a history of hypertension in the city of Padangsidimpuan at the time of the study (data collection time), namely January - July 2018 , it was found that there were 20 pregnant women, who were divided into two groups of the same size, ie 10 people per group. The research flow were:

a. Prospective study participants were primigravida pregnant women by providing prior information about the research objectives. Those who agree to take part in the research are asked to sign the consent letter that has been provided.

b. Then divided into intervention and control groups.

c. Aerobic exercise is carried out 2 times a week with a duration of 30 minutes each exercise, for 12 weeks, starting from 16 weeks of pregnancy. 
d. Exercise was carried out during classes for pregnant women.

Blood pressure was calculated before and after the intervention or aerobic exercise for 12 weeks was completed. The control group did not get any treatment but their blood pressure was still measured. The type of delivery seen at the end of pregnancy.

\subsection{Research Design}

This type of research was a quasy experimental study with a pre and post control group design to determine the effect of aerobic exercise initiation on blood pressure and type of labor. The intervention group was primigravida with a history of hypertension with aerobic exercise intervention, the control group was primigravida mothers with a history of hypertension without intervention.

\subsection{Data Management and Analysis}

The measurement results are collected and processed through the process of editing, coding, data entry, then data processing was carried out. Data processing was done by computer. Data analysis used univariate and bivariate analysis to determine the characteristics and data distribution of each variable, by compiling frequency tables for blood pressure, type of delivery, and characteristics of research subjects. Bivariate analysis was performed by t-test.

\section{Results}

\subsection{Recruitment}

This research was conducted in the city of Padangsidimpuan from March 2018 to October 2018.

After conducting observations, there were as many as 20 primigravidas who met the inclusion criteria. 10 pregnant women who would be given aerobic exercise were called the intervention group and 10 pregnant women who were not treated were called the control group.

\subsection{Characteristics of Respondents}

Table 1. Characteristics of respondents

\begin{tabular}{llll}
\hline Characteristics & Intervention & Control & $p$ \\
& Mean \pm SD & Mean \pm SD & $p>0,05$ \\
\hline Age & $27,4 \pm 2,1$ & $25,8 \pm 3,2$ & $p>0,05$ \\
Sistolic & $147,7 \pm 9,0$ & $153,3 \pm 10,1$ & $p>0,05$ \\
Diastolic & $96,3 \pm 7,8$ & $97,8 \pm 7,7$ & $p$ \\
\hline
\end{tabular}

Based on its characteristics, the mean age of the respondents was 27.4 years for the intervention group and 25.8 years for the control group. The systolic mean of respondents was $147.7 \mathrm{mmHg}$ for the intervention group and $153.3 \mathrm{mmHg}$ for the control group. The diastolic mean of respondents was $96.3 \mathrm{mmHg}$ for the intervention group and $97.8 \mathrm{mmHg}$ for the control group. Statistically, using the Mann-Whitney technique, there was no significant difference between the two groups with a $\mathrm{p}$ value $>0.05$.

\subsection{Effect of Aerobic Exercise on Primigravida Mother's Systolic}

Table 2. Effect of Aerobic Exercise after 12 weeks on Mean \pm SD systolic for primigravida mother

\begin{tabular}{lll}
\hline & Mean \pm SD $(\mathrm{mmHg})$ & $p$ \\
\hline Intervention Group & $154,7 \pm 14,7$ & 0,54 \\
Control Group & $156,1 \pm 12,1$ & \\
\hline
\end{tabular}

Table 2 showed that the systolic mean after 12 weeks in the intervention group was lower than that in the control group. The mean systolic in the intervention group was $154.7 \pm 14.7$ and the mean systolic in the control group was $156.1 \pm 12.1$. Statistically, using the Mann-Whitney technique, there was no significant difference with a $p$ value of $0.54(<0.05)$. 


\subsection{Effect of Aerobic Exercise on Diastolic in Primigravida Mothers}

Table 3. Effect of Aerobic Exercise after 12 weeks of Diastolic Mean \pm SD of primigravida mother

\begin{tabular}{lll}
\hline & Mean $\pm \mathrm{SD}(\mathrm{mmHg})$ & $p$ \\
\hline Intervention & $94,4 \pm 7,1$ & 0,1 \\
Control & $97,9 \pm 7,8$ & \\
\hline
\end{tabular}

Table 3 showed the diastolic mean after 12 weeks in the intervention group was $94.4 \pm 7.1 \mathrm{mmHg}$ and in the control group $97.9 \pm 7.8 \mathrm{mmHg}$. The diastolic mean in the intervention group was lower than in the control group, but statistically, using the Mann-Whitney technique there was no significant difference with a $p$ value $>0.05$.

\subsection{The Effect of Aerobic Exercise on Types of Labor of Primigravida Mothers}

Table 4. Effect of Aerobic Exercise on Type of Labor of Primigravida Mothers

\begin{tabular}{lccc}
\hline & \multicolumn{3}{c}{ Type of Labor } \\
\cline { 2 - 4 } & Normal & Sectio Caesarea & $p$ \\
\hline Intervention & - & 10 & 0,5 \\
Control & - & 10 & \\
\hline
\end{tabular}

Table 4 showed that all samples in both the intervention group and the control group all experienced labor with action, namely Caesarean section. Statistically, using the Mann-Whitney technique, there was no significant difference with a $\mathrm{p}$ value $<0.05$.

\section{Discussion}

The measurement results obtained from the mean age, systolic and diastolic were almost the same or homogeneous in the two groups. The systolic mean after intervention was lower than the control group, but statistically there was no significant difference. The same thing also happened to diastolic, where the diastolic mean in the intervention group was lower than in the control group even though there was no statistically significant difference. All respondents, both in the intervention group and in the control group, underwent a type of delivery with action.

Overall, the characteristics of the respondents, namely mean age, mean systolic blood pressure and mean diastolic blood pressure, showed results that were not significantly different between the intervention group and the control group. This shows the homogeneity between the two groups. All respondents in this study were primigravidas. According to Bobak (2005), approximately $85 \%$ of preeclampsia occurred in the first pregnancy (primigravida).

Primigravidas often experience stress in the face of childbirth. Emotional stress that occurs in primigravida causes an increase in the release of corticotropic-releasing hormone (CRH) by the hypothalamus, which in turn causes an increase in cortisol. The effect of cortisol is to prepare the body to respond to all stressors by increasing sympathetic responses, including responses aimed at increasing cardiac output and maintaining blood pressure. In women with preeclampsia-eclampsia, there is no decrease in sensitivity to these vasopeptidavasopeptides, so a large increase in blood volume directly increases cardiac output and blood pressure (Bobak, 2005).

In this study, it was found that respondents in the intervention group mean systolic blood pressure after 12 weeks was $154.7 \pm 14.7 \mathrm{mmHg}$ and in the control group $156.1 \pm 12.1 \mathrm{mmHg}$. Statistically, using the Mann-Whitney technique, there is no significant difference with $\mathrm{p}$ value $>0.05$.

The mean diastolic blood pressure after 12 weeks after intervention in the intervention group was $94.4 \pm 7.1$ and the control group was $97.9 \pm 7.8 \mathrm{mmHg}$. Statistically, using the Mann-Whitney technique, there is no significant difference with $\mathrm{p}$ value $>0.05$.

In this study, it was found that after doing aerobic exercise for 12 weeks, systolic blood pressure was lower than in the intervention group, diastolic blood pressure was lower than in the control group but it was not statistically significant.

Systolic and diastolic blood pressure measurements were carried out every week but the data analyzed were only the results of the first measurement at the start of the activity and the last measurement after 12 weeks. The 
duration of each exercise is 5-10 minutes. Blood pressure measurements were taken before and after the activity. There was an increase and decrease in blood pressure in both the intervention group and the control group during the 12 weeks of activity. Aerobic exercise is carried out at the health center and at the midwife's house, so that the implementation can be controlled. All pregnant women enter a state of pre-eclampsia.

In line with Da Silva's study which examined normal pregnant women, it was found that there was no difference in the incidence of pre-eclampsia in the aerobic exercise intervention group and the control group, but the incidence of pre-eclampsia was lower in the intervention group than in the control group (Da Silva, 20017).

Scholten (2014) who examined the effects of aerobic exercise on pregnant women with a history of pre-eclampsia with a control group who were normal pregnant women, found that aerobic exercise made no difference in systolic and diastolic pressure between the intervention group and the control group, even though it was before aerobic exercise intervention. performed, the mean systolic and diastolic blood pressure in the intervention group was higher than in the control group. Therefore Scholten recommends aerobic exercise to be done in pregnant women with a history of hypertension.

A schoten study with a sample of the intervention group, namely pregnant women with a history of pre-eclampsia and a control group with normal pregnant women, found that aerobic exercise could improve their risk of heart blood vessel problems and improve their heart health. These improvements included metabolic syndromes in both groups experiencing reduced stress on biochemical blood vessels. The effect of exercise on heart protection after childbirth in both study groups was caused by improvements in endothelial function, improvements in blood vessel wall thickening and improvements in the structure of blood vessels (Scholten, 2014).

In line with the results of Berghella's research which concluded, by doing aerobic exercise there will be a decrease in oxidative stress so that it will improve endothelial function, and will have an effect on preventing the occurrence of pre-eclampsia. Aerobic exercise also reduces the risk of childbirth by cesarean section and increases the incidence of vaginal delivery (Berghella, 2017).

However, exercise cannot normalize blood vessels in pregnant women with a history of pre-eclampsia, but what is interesting is that exercise will induce blood vessel repair in both the sample group of pregnant women with a history of pre-eclampsia and the control group of normal pregnant women. Exercise also has the potential to detect risks or problems in pregnant women and result in reduced costs for screening for mothers. Exercise also causes a reduced risk of experiencing pre-eclampsia again in the next pregnancy (Scholten, 2014).

Aerobic exercise is a sport that can be used to reduce the incidence of gestational hypertension. Because of its benefits, aerobic exercise should be used as a lifestyle during pregnancy and after childbirth because of its health benefits (Magro, 2017).

Kasawara in his research the effect of aerobic exercise by cycling is safe for normal pregnant women and pregnant women with a history of pre-eclampsia, and does not cause problems with fetal outcomes and maternal outcomes (Kasawara, 2013).

However, the results of this study are different from the results of the current study, namely that all respondents gave birth with the type of delivery by action. Perhaps this is because all respondents are high-risk primigravida mothers. However, the interesting thing that was found by the researchers was that all respondents, both the intervention group and the control group, were also found after 20 weeks of gestation that edema and urine protein were found. All mothers were categorized as Superimposed Preeclampsia.

\section{Conclusions}

Systolic and diastolic blood pressures were lower in the intervention group than in the control group but not statistically significant. All respondents have a type of delivery by action.

\section{Suggestions}

The need to socialize the benefits of aerobic exercise during pregnancy, which is given to pregnant women during antenatal classes. It is recommended that all health institutions and midwifery practitioners routinely do exercise in classes for pregnant women to support the smooth running of the labor process.

\section{Acknowledgments}

The researcher thanks the Indonesian Ministry of Health for financially supporting this research.

\section{Competing Interests Statement}

The authors declare that there are no competing or potential conflicts of interest. 


\section{References}

Arizabaleta, A. V. M., Buitrago, L. O., Plata, A. C. A., Escudero, M. M., \& Velez, R. R. (2010). Aerobic Exercise During Pregnancy Improves Healt-related quality of life: a randomised trial. Journal of Physiotherapy, 56. 2010. https://doi.org/10.1016/S1836-9553(10)70008-4

Asker, S. A., Abdelazeim, F. A., Zaky, N. A., \& Wageh, A. (2018). The Effect of Maternal Exercise Program On Fetal Growth In Pre eclampsia: A Prospective Randomised Controlled Clinical Trial. Bulletin of Faculty of Physical Therapy, 23, 36-42.

Barakat, R., Pelaez, M., Cordero, Y., Perales, M., Lopez, C., Coteron, J., \& Mottola, M. F. (2016). Exercise during pregnancy protects against hypertension and macrosomia: randomized clinical trial. American Journal of Obstetrics and Gynecology, 214(5), 649.e1-649.e8. https://doi.org/10.1016/j.ajog.2015.11.039

Berghella. (2017). Exercise In Pregnancy. Am I Obstet Gynecol. https://doi.org/10.1016/j.ajog.2017.01.023

Bobak, D. (2005). Buku Ajar Keperawatan Maternitas. Jakarta: EGC.

Cunningham, F. G. (2010). Obstetri William Edisi, 21. Jakarta: EGC.

da Silva, S. G., Hallal, P. C., Domingues, M. R., Bertoldi, A. D., da Silveira, M. F., Bassani, D., ... \& Evenson, K. (2017). A randomized controlled trial of exercise during pregnancy on maternal and neonatal outcomes: results from the PAMELA study. International Journal of Behavioral Nutrition and Physical Activity, 14(1), 1-11. https://doi.org/10.1186/s12966-017-0632-6

Genest, D. S., Falcao, S., Gutkowska, J., \& Lavoie, J. L. (2012). Impact of exercise training on preeclampsia: potential preventive mechanisms. Hypertension, 60(5), 1104-1109. https://doi.org/10.1161/HYPERTENSIONAHA.112.194050

Kasawara, K. T., Burgos, C. S. G., do Nascimento, S. L., Ferreira, N. O., Surita, F. G., \& Pinto e Silva, J. L. (2013). Maternal and perinatal outcomes of exercise in pregnant women with chronic hypertension and/or previous preeclampsia: a randomized controlled trial. International Scholarly Research Notices, 2013. https://doi.org/10.1155/2013/857047

Magro-Malosso, E. R., Saccone, G., Di Tommaso, M., Roman, A., \& Berghella, V. (2017). Exercise during pregnancy and risk of gestational hypertensive disorders: a systematic review and meta-analysis. Acta obstetricia et gynecologica Scandinavica, 96(8), 921-931. https://doi.org/10.1111/aogs.13151

Di Mascio, D., Magro-Malosso, E. R., Saccone, G., Marhefka, G. D., \& Berghella, V. (2016). Exercise during pregnancy in normal-weight women and risk of preterm birth: a systematic review and meta-analysis of randomized controlled trials. American journal of obstetrics and gynecology, 215(5), 561-571. https://doi.org/10.1016/j.ajog.2016.06.014

Mansjoer, A. (2008). Kapita Selekta Kedokteran. Jakarta: Media Aesculapius.

Prasetyowati, S. (2012). Hubungan Antara Preeklampsi Dengan Persalinan Tindakan. 2012.

Sastroasmoro, S., \& Ismael, S. (2011). Dasar-dasar metodologi penelitian klinis. Jakarta: sagung seto, 31-63.

Scholten, R. R., Thijssen, D. J., Lotgering, F. K., Hopman, M. T., \& Spaanderman, M. E. (2014). Cardiovascular effects of aerobic exercise training in formerly preeclamptic women and healthy parous control subjects. American journal of obstetrics and gynecology, 211(5), 516-e1. https://doi.org/10.1016/j.ajog.2014.04.025

Survei demografi dan kesehatan Indonesia (SDKI). Laporan pendahuluan. Jakarta: 2012.

Sorensen, T. K., Williams, M. A., Lee, I. M., Dashow, E. E., Thompson, M. L., \& Luthy, D. A. (2003). Recreational physical activity during pregnancy and risk of preeclampsia. Hypertension, 41(6), 1273-1280. https://doi.org/10.1161/01.HYP.0000072270.82815.91

Yeo, S., Steele, N. M., Chang, M. C., Leclaire, S. M., Ronis, D. L., \& Hayashi, R. (2000). Effect of exercise on blood pressure in pregnant women with a high risk of gestational hypertensive disorders. The Journal of reproductive medicine, 45(4), 293-298.

\section{Copyrights}

Copyright for this article is retained by the author(s), with first publication rights granted to the journal.

This is an open-access article distributed under the terms and conditions of the Creative Commons Attribution license (http://creativecommons.org/licenses/by/4.0/). 